\title{
GENDER AND DISABILITY INCLUSION IN POST-DISASTER REBUILDING 'BUILD BACK BETTER' PROGRAMMES IN SRI LANKA: A LITERATURE REVIEW
}

\author{
MENDIS A.P.K.D. ${ }^{1}$, THAYAPARAN MENAHA ${ }^{2} \&$ KALUARACHCHI YAMUNA ${ }^{3}$ \\ 1,2Department of Building Economics, University of Moratuwa, Colombo, Sri Lanka \\ 3 School of the Built Environment and Architecture, London South Bank University, London, United Kingdom \\ 1dhaneeshamendis@gmail.com,15243of@uom.lk, ${ }^{2} m$ thayaparan@uom.lk,3Yamuna.Kaluarachchi@lsbu.ac.uk
}

\begin{abstract}
In the last decade, many South Asian developing countries have suffered natural disasters. Severe disaster destruction results in an overwhelming need to rebuild housing and infrastructure within a brief amount of time. United Nation Development Programme has sought to make this reconstruction program a "Build Back Better (BBB)" opportunity, hence gender inequality and marginalisation of people with disabilities remain a problem in many countries. Although the international community has sought to promote this resilience and inclusion, the Post-Disaster Rebuilding (PDR) process still overlooks these sectors of society and their needs. Therefore, this paper aims to bring in literature synthesis addressing gender and disability inclusion in PDR 'BBB' programmes in Sri Lanka. Besides, involvement in the mitigation of vulnerability and community resilience to disaster risks and relocation was found to play a significant role. Vulnerability and the risk of disasters can be dramatically reduced by ensuring a culture of disaster prevention and resilience for all segments of populations, particularly rural areas, girls and women, and the disabled. All aspects of socially inclusive, formal, and nonformal commitments are important to take their desires and requirement into consideration.
\end{abstract}

Keywords: Build Back Better (BBB); Disability; Gender; Post-Disaster Rebuilding (PDR).

\section{Introduction}

During the past decade, many developed countries have experienced several natural disasters in South Asia (Bangladesh, Sri Lanka, Pakistan, and India) (United Nations Office for Disaster Risk Reduction [UNDRR], 2019). The physical destruction that accompanies disasters creates an urgent need to rebuild housing and infrastructure facilities within a short time (Kennedy et al., 2008). United Nations Development Programme (UNDP) has tried to make this re-building programme an opportunity to 'Build Back Better (BBB)' (UNDP, 2009), where the built environment responds to the needs of many and long-term sustainability, contributing to the re-settlement and healing process of the community. To safeguard a resilient and sustainable recovery, the Sendai Framework for Disaster Risk Reduction and more broadly, the Sustainable Development Goals, emphasise that Disaster Risk Management (DRM) and development planning should be inclusive of all fragments of the society comprising gender, disable, vulnerable and marginalised (UNDRR, 2019). Even though the international community has attempted to embrace this resilience and inclusion, in practice, these segments of the society and their needs are often overlooked throughout the re-building process (Robles, 2019).

In Post Disaster Rebuilding (PDR) Programmes in South Asia, adequate gender and disability data is hard to come by. Further, this is even more difficult when disability perspectives are still largely marginalised in existing DRM planning and programming (Drolet et al., 2015). Limitations in obtaining reliable gender and disability data are due to several factors including the inadequacy of tools used to capture data, constraints in obtaining information about disability registrations, low prioritisation, and social stigma, among others (United Nations, 2019). Given this context, any initiative to promote and support gender and disability inclusion must undertake measures to understand conditions that hinder or enable participation of women and men with disabilities in PDR.

Sri Lanka has been affected by multiple disasters triggered by both natural and manmade hazards. Besides, the recent floods and landslides in Sri Lanka in May 2017 contributed to an extensive economic loss and damage to communities and their assets. The country faced its worst natural disaster by the Indian Ocean tsunami in 2004 and droughts in 2016 and 2017 (Wickramaratne et al., 2012). Further, Sri Lanka fought a civil war for decades that ended in 2009 and the reconciliation 
process in the post-war situation is still underway (Ministry of National Policies and Economic Affairs, 2016). Hence it is a unique location to initiate research that contributes to the wider 'BBB' programme and the inclusivity in PDR. Besides, though there are studies carried out on PDR 'BBB' programmes worldwide, less attention had been paid for gender and disability inclusion. Moreover, there is a dearth of literature on gender and disability inclusion in PDR 'BBB' programmes in the Sri Lankan context. Thus, this paper aims to bring in literature synthesis addressing gender and disability inclusion in PDR 'BBB' programmes in Sri Lanka.

\section{Methodology}

A comprehensive literature synthesis was adopted as the key methodology based on which this paper is produced. Saunders, Lewis, and Thornhill (2016) found that a robust literature will make sure that new research-related information is contextual and that the study creates original expertise that is missing from existing literature. A thorough literature review is, therefore, necessary to gather current information in the research field and pave the way for new information to be discovered. Hence the authors reviewed key relevant literature on major databases. The disaster management was considered as a discipline in Sri Lanka after the Indian Ocean Tsunami in 2004 and the BBB concept was initiated in 2006. Hence the literature focused on the journal articles and reports that were published since 2004. The authors have filtered the articles based on their relevancy to the research using keywords such as 'Build Back Better (BBB), Disability, Gender, Post-Disaster Rebuilding (PDR)'. The focus was also given on reports published by Sri Lankan authorities.

\section{Literature Review}

\subsection{DISASTER MANAGEMENT}

In 2017, the United Nations General Assembly (2017) officially accepted a definition of a disaster as "a serious disruption of the functioning of a community or a society at any scale due to hazardous events interacting with conditions of exposure, vulnerability, and capacity, leading to one or more of the following: human, material, economic and environmental losses, and impacts". In recent decades, the frequency and severity of natural disasters in Sri Lanka have increased considerably (Amaratunga et al., 2020). Natural disasters including landslides, floods, tsunami, high winds, and droughts have caused human, physical, financial, and environmental casualties and have had significant impacts on Sri Lanka's economy (Steele et al., 2007). In particular, the three most common natural disasters which occur every year in Sri Lanka include floods, droughts, and landslides, which impact people's lives and livelihoods of a significant number of people. Based on available data, between 2009 and 2018, about 1,98 million people were affected every year by flooding, droughts, and landslides (Basnayake et al., 2019). Moreover, the distribution of impacts depends on the level of physical, social, and economic vulnerability to natural disasters of a given area (Wickramasinghe, 2014). It highlights the need to figure out how to be more disaster resilient in the future (Amaratunga et al., 2020).

'Disaster management'; basically meant 'disaster risk management' encompasses all activities which reduce the losses of life, property, or assets related to disasters by either reducing the danger or vulnerabilities of risk components (Khan, Vasilescu and Khan, 2008). According to the United Nations Office for Disaster Risk Reduction, disaster risk management focuses on organising and managing all emergencies and disaster responsibilities, including preparation, reaction, and initial recovery actions (UN Spider, 2019). Moreover, it covers the total of all actions, programmes, and measures that can be undertaken before, during, and after disasters to prevent, reduce and recover from disasters (Haigh and Amaratunga, 2010).

Pre-disaster activities are carried out to reduce possible consequences for human and property casualties. The measures taken at this level to reduce risks are called mitigation and preparedness (Khan, Vasilescu and Khan, 2008). During a disaster, initiatives are taken to minimise the needs and supplies of victims. Activities under this level are called emergency intervention (Enshassi, Shakalaih and AlKilani, 2018). In the post-disaster phase, steps are taken to respond to a disaster to recover and rehabilitate communities promptly after the disaster. These are known as response and recovery 
activities (Salamati Nia and Kulatunga, 2017). In disaster management, the PDR phase is challenged with many obstacles in rending the disaster a chance for development because of its ineffectiveness and inefficiency.

\subsection{POST DISASTER REBUILDING}

Rebuilding is a redevelopment indicator that not only involves the development of physical structures, but also the development and rebuilding of confidence, compassion for one's self, autonomy, support for one another, and mutual trust. This long-term process focuses on the development of human and material resources, coordinated independence efforts, sustainability, and inclusiveness (Thurairajah, Amaratunga and Haigh, 2008). Even though the reaction to emergencies has improved, permanent reconstruction is often managed inefficiently, improperly coordinated, and slowly to get off the ground (Jones, 2006). Yet the PDR is a significant stage of disaster recovery that offers a window of opportunity for the development of the community. According to Halvorson and Hamilton (2009), post-disaster operations tend to be inefficient and poorly handled despite the enormous amount of disaster events, which require enhancement. Kennedy et al. (2008) pointed out that reconstruction of the built environment and infrastructure only as it was before a disaster also regenerates the same past vulnerabilities. Moreover, if the pre-disaster standard were restored, communities affected by disasters would encounter the same problems, if in the future they were exposed to another disaster. The post-disaster reconstruction and recovery duration offers a chance to address the vulnerabilities in communities appropriately (Thurairajah, Amaratunga and Haigh, 2008).

A concept began to emerge that after the disaster, rebuilding should be used, not only to rebuild what was damaged, and to restore the community to the pre-disaster state, but also to take the opportunity to improve physical, social, environmental, and economic conditions to create a new state of standards (Boano, 2009). This was called "Build Back Better (BBB)", which suggests that successful recovery in communities after disasters should combine the recovery and improvement of the constructed environment with psychological, social, and economic climatic conditions in a holistic way, to improve the resilience of the entire community (Clinton, 2006).

\subsection{BUILD BACK BETTER CONCEPT}

The term "Build Back Better" became common after a major rebuilding project after the Indian Ocean tsunami tragedy in 2004, after which the BBB recommendations for advice on rehabilitation and restoration were more explicitly implemented to accomplish the goal (Clinton, 2006; Mannakkara et al., 2014). BBB implies an ideal process for reconstruction and recovery that provides disaster-affected communities with resilient, sustainable, and efficient recovery solutions. The motivation behind the $\mathrm{BBB}$ principle is to reinforce and recover societies after a disaster (Mannakkara, 2015). In order to build better back on the local condition of the impacted population, the first step in PDR activities is to consider needs evaluations and surveys to provide the necessary assistance to support the population (Khasalamwa, 2009). Moreover, the policies of reconstruction and recovery must be formulated based on local requirements for the preservation and protection of local culture. Batteate (2006) stated that maintaining community participation is essential to BBB's success throughout recovery. Literature has emphasised the importance of decentralisation in enabling disaster communities to take responsibility for recovery efforts and be involved in policy-making (Mannakkara, Wilkinson and Francis, 2014).

The BBB principle reflects the government's idea of a resilient Sri Lanka too in the event of a disaster. As such UNDP in Sri Lanka, the National Building Research Organisation (NBRO), which is part of this proposal initiative, has collaborated to introduce a series of training and education programmes, which concentrate on BBB principles (UNDP, 2018). UNICEF has also set up a 3-year Tsunami Recovery Plan for 2005-2007 in the 10 most-affected districts in Sri Lanka, including the construction and rehabilitation of 36 health centres, water supply, and sanitation rehabilitation facilities as well as improvement, the building of 26 schools for the children, and the repair and building of 77 social care facilities for children emphasising the BBB concept (United Nations Children's Fund, 2005). 10 prepositions were introduced in BBB principles (Clinton, 2006), and the $2^{\text {nd }}$ principle highlights that recovery must promote fairness and equity, which denotes that the equal consideration should be 
given to the marginalised groups such as women and disabled people in PDR. Therefore the next section will describe the real need for the consideration of gender and disability inclusion in BBB programmes.

\subsection{THE NEED FOR GENDER AND DISABILITY INCLUSION IN DISASTER RECOVERY IN THE} PERCEPTION OF 'BUILD BACK BETTER' PROGRAMMES

It has been noted that most of the time disasters have a significant impact on those impacted, particularly for the most vulnerable communities (Sharma, 2014). Disabled people are now facing heightened challenges in crises in comparison to the rest of the population, in particular, because their social and physical environments offer opportunities to maintain and rehabilitate them (United Nations Economic and Social Commission for Asia and the Pacific [UNESCAP], 2015). Recognition of the systemic roots of disaster risks, rooted in the same processes that lead to social inequality, poverty, and exclusion, is a suitable lens for understanding why disasters tend to affect people with disabilities more severely (Tierney, 2015). Furthermore, it generates a discussion on how changing social and environmental conditions are vital to achieving the goal of rebuilding for the 'better' (Zayas et al., 2017).

Disability is found to worsen the social impact of disasters, especially for women and girls who suffer from both disability and gender impediments (Enarson, 2009). Studies also have shown a higher prevalence of physical harassment and relationship violence among people with disabilities, problems that have been worsened in post-disaster settings. Cultural standards can already impede female mobility and access to disaster assistance in many societies (Zayas et al., 2017), and this made it harder for disabled women to receive much-needed assistance and help if a disaster hits. Unfortunately, current policy procedures are often insufficient to address the multifaceted experiences of exclusion in the form of gender and disability, especially in disaster rehabilitation (Sharma, 2014). It was mentioned that while in some countries 'BBB' recovery initiatives are being implemented, physical environment barriers continue to persist (Khasalamwa, 2009). Most of the areas assessed were either not wheelchair accessible or contain obstacles to mobility along paths. Besides, many of the installations evaluated lacked handrails. In addition, comfort rooms often were not built to meet the needs of disabled persons, especially women. Public areas were not particularly suitable for the visually impaired. No tactile floors or braille labels provided the required directions or orders. The lack of signals is often disadvantageous for those with hearing disabilities. There were no trained personnel or employees in any of these institutions or public places to provide mobility assistance and information (Zayas et al., 2017). Moreover, Disaster Recovery Guidance Note (Robles, 2019) has addressed the various post-disaster challenges that women face in recovery and rebuilding due to underlying inequalities and marginalisation issues. Besides, the note guided on how to transform the post-disaster situation into an opportunity for gender equality and women's empowerment, with a focus on "BBB," because new progressive gender roles and relationships can emerge aftermath of a disaster.

Since the 2004 tsunami disaster in the Indian Ocean has made BBB a symbol for disaster relief and restoration, it is worth questioning if populations are truly more positive if the process of recovery tends to shut out disadvantaged sectors such as women and people with disabilities. Besides, the concept of BBB has been advocated not only to rehabilitate and strengthen infrastructure and to rebuild systems and means of livelihoods but also to rehabilitate disabled people, women, girls, children, and men in the community concerned in a way which includes them (Kennedy et al., 2008). It was stressed that "the BBB" criteria would include ways to mitigate gender inequality and improved equality by taking into account the needs found in the appraisal by recover, rebuild and pay lost properties and damages (Robles, 2019). This section presented the significance of gender and disability inclusion in BBB programmes. In order to make the inclusion effective and practical, it is necessary to have the policy level support in BBB programmes. Accordingly, the next section reviews the policies related to gender and disability inclusion. 


\subsection{POLICIES RELATED TO GENDER AND DISABILITY INCLUSION}

The international policy frameworks covering the problem of increased disaster risk have evolved following the declaration of the International Decade on Natural Disaster Reduction in 1989 by the United Nations General Assembly Resolution 44/236. From the virtual inability to identify the unequal circumstances in the economically 'vulnerable' classes to the current comments on the need to consider disadvantaged industries, views on what defines and is better handled in disaster risk inevitably change towards more constructive participation and interaction of the local populations and social groups (Zayas et al., 2017). While gender mainstreaming has been a continual work for gender scholars and advocates since the 1990s (Enarson and Meyreles, 2004), in reality, the integration of gender into disaster risks management and planning is largely an "unfinished" business, or even "unstarted" business in some parts of the world (Seager, 2014). Likewise, the international arena has fairly recently taken the inclusion of disability viewpoints with disaster risk management.

The Hyogo Framework for Action 2005-2015 for mitigating disaster in the aftermath of the 2004 Indian Ocean tsunami, became more mindful of the need for "vulnerable people' to cope with threats, but only addresses disabled person (Priestley and Hemingway, 2007; United Nations International Strategy for Disaster Reduction, 2005). The Sendai Framework for Disaster Risk reduction 20152030, which was set up in conjunction with other vulnerable groups, such as women and children, during the Third World Conference on Disaster Risk Reduction, is more explicit in the inclusion of persons with disabilities (United Nations, 2015). Here, women and people with disabilities are listed as core players in the processes of disaster risk management planning and implementation (United Nations, 2015). More specifically, it supports accessibility as an important factor in ensuring the successful participation of disabled persons. In Sri Lanka, the NBRO also works on promoting the Sendai Framework, especially for Priority three to invest in reducing resilience risks from disasters.

Since disaster risk management is unavoidably related to development processes, gender and the inclusion of people with disabilities are also obvious in the establishment of the Sustainable Development Goals, the United Nations Convention on the Rights, and the Incheon strategy "making the right real" for disabled people in Asia and the Pacific 2013-2022, among others (UNESCAP, 2012). The global framework that has evolved so far from attempts to advocate and campaign for women and people with disabilities provides the institutional driving forces for more equitable disaster risk management and development planning initiatives (Zayas et al., 2017). These global developments also serve as the basis for some of Sri Lanka's policy structures dealing with gender and disability in the management of disasters risk. Such as; Disaster Management Act (2005), National Policy on Disaster Management (2010), Convention on the Rights of Persons with Disabilities, National Action Plan for Disability, Gender Action Plan, The Roadmap for Disaster Risk Management (2006-2016), Sri Lanka National Disaster Management Plan (2013-2017), Comprehensive Disaster Management Programme (2014-2018), National Adaptation Plan for Climate Change Impacts in Sri Lanka (20162025), and (Draft) National Disaster Risk Management Plan (2018-2030). In Sri Lanka, the Disaster Management Act, National Policy on Disaster Management, the Roadmap for Disaster Risk Management, Sri Lanka National Disaster Management Plan, Comprehensive Disaster Management Programme, National Adaptation Plan for Climate Change Impacts in Sri Lanka, and National Disaster Risk Management Plan have given attention for marginalised groups especially for women and disabled people in PDR processes. Besides, there are some action plans in Sri Lanka, which highlights separately the inclusion of women's needs as well as the needs and rights of disabled people.

\subsection{CONCEPTUAL FRAMEWORK ON STAKEHOLDER MAPPING}

It has been recognised that, during PDR preparation, governance, and development, all individuals and communities impacted by disasters should actively take part in decision-making (Drolet et al., 2015). Following the Sri Lanka Disaster Management Act No 13 of 2005, which was passed by the Parliament of Sri Lanka on 13th May 2005, the Disaster Management Centre (DMC) was established. The DMC is currently working under the jurisdiction of the Ministry of Disaster Management and Human Rights. Besides, DMC must coordinate and cooperate with the ministries, departments, local authorities, Grama Niladhari divisions, armed forces, police, and foreign Non-Governmental 
Organisations (NGOs) to handle the overall risk management process in Sri Lanka (Ministry of Disaster Management, 2009). In Sri Lanka, the stakeholders can be categorised into three levels such as local, provincial/district, and national level. In each level, there are three different communication and commanding line in between the stakeholders. They are top-down, bottom-up, and both ways. However, in the post-disaster recovery processes, the participatory and bottom-up approach led by impacted communities has strong potential to help meet their needs (Drolet et al., 2015). Based on the initial understanding on the national and local governance structure, a conceptual framework on stakeholder mapping was developed by the authors as shown in Figure 1. The purpose of the conceptual framework is to understand the relationships between the key stakeholders involved in PDR and explore the level of implementation of the policies related to gender and disability at national, provincial, district, and local level activities.

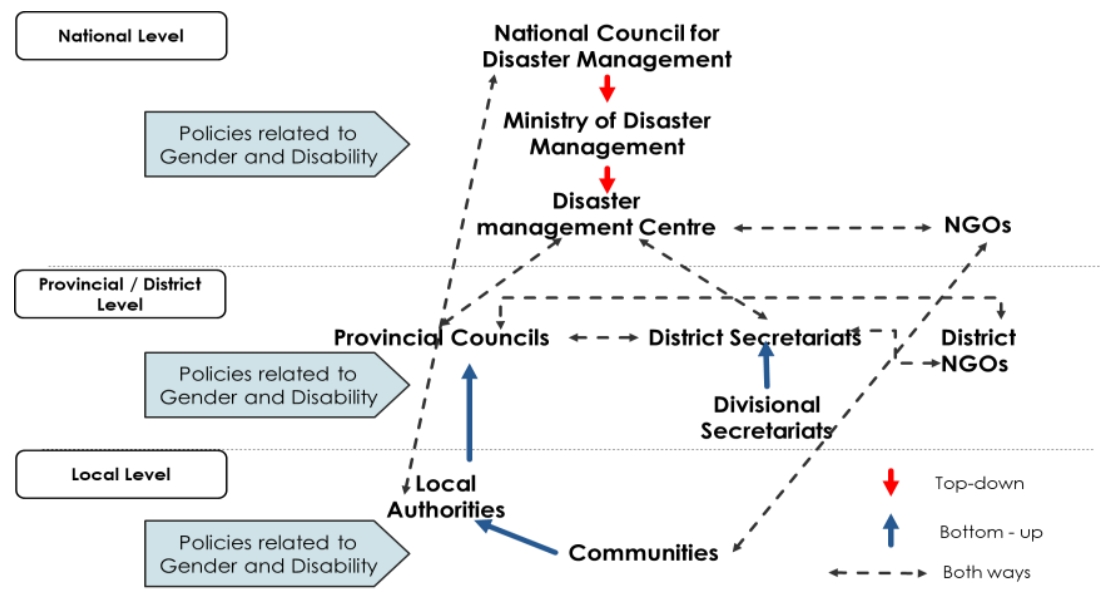

Figure 1, Conceptual framework on stakeholder mapping

This conceptual framework will be used to collect primary data through stakeholder interviews, which will be the next phase of this research. The intention is to refine the conceptual framework by elaborating on the communication and commanding line between the stakeholders in the context of PDR and identifying the specific policies related to gender and disability at different levels. The refined stakeholder interviews informed framework will present a clear stakeholder mapping to this research.

\section{Conclusions}

Multiple disasters, both natural and man-made, have affected Sri Lanka. The Indian Ocean tsunami in 2004 and droughts in 2016 and 2017 confronted the country with its most serious natural disaster. Moreover, for decades that came to an end in 2009, Sri Lanka fought a civil war and the post-war reconciliation process is still underway. Moreover, gender discrimination and marginalisation of people with disabilities remain an issue in many South Asian countries in any post-disaster circumstances. PDR extends beyond the building of new houses as the efforts to fix some issues would be challenging without knowing state, political or cultural dynamics. 'BBB' rebuilding was often linked to restoration of infrastructure and facilities, often without much gender and disability consideration. In the light of current and future disaster threats, gender and disability, and other social problems that intersect to create disaster risk, 'BBB' needs to be dealt with by efforts at disaster recovery that ensures that nobody is left behind. According to the literature findings, humanitarian agencies' interventions attempt to address these important aspects, but not entirely since they are beyond the range of many external risk factors and need collaboration with other stakeholders, particularly with the Sri Lankan government. Further, this paper will, therefore, offer a profound overview of the governance process followed in rebuilding and highlighting shortcomings and steps to include to improve the involvement of different segments of the community, including gender and persons with disabilities. 


\section{References}

Amaratunga, D. et al. (2020) How do we organise for disaster risk reduction and resilience? A study on disaster reduction and management governance profile of Sri Lanka. United Kingdom: University of Huddersfield.

Basnayake, A. et al. (2019) Disaster management in Sri Lanka: A case study of administrative failures. Available at: https://www.veriteresearch.org/wp-content/uploads/2019/o7/Verité-Research_Disaster-Management-in-Sri-Lanka-ACase-Study-of-Administrative-Failures.pdf.

Batteate, C. (2006) 'Cal Poly's symposium on urban disaster risk reduction and regeneration planning: An overview', Focus, 3(1), pp. 11-17. doi: 10.15368/focus.2006v3n1.1.

Boano, C. (2009) 'Housing anxiety and multiple geographies in post-tsunami Sri Lanka', Disasters, 33(4), pp. 762-785. doi: 10.1111/j.1467-7717.2009.01108.x.

Clinton, W. J. (2006) Lessons learned from tsunami recovery: Key propositions for building back better. New York. Available at: https://www.preventionweb.net/files/2054_VL108301.pdf.

Drolet, J. et al. (2015) 'Women rebuilding lives post-disaster: Innovative community practices for building resilience and promoting sustainable development', Gender and Development, 23(3), pp. 433-448. doi: 10.1080/13552074.2015.1096040. Enarson, E. (2009) Women, gender, and disaster: Abilities and disabilities. London. Available at: https://www.gdnonline.org/resources/GDN_GenderNote4_Abilities.pdf.

Enarson, E. and Meyreles, L. (2004) 'International perspectives on gender and disaster: Differences and possibilities', International Journal of Sociology and Social Policy, 24(10), pp. 49-93. doi: 10.1108/01443330410791064.

Enshassi, A., Shakalaih, S. and AlKilani, S. (2018) 'Strategies for community participation in pre-disaster phase in the Gaza Strip, Palestine', Journal of Construction in Developing Countries, 23(2), pp. 107-127. doi: 10.21315/jcdc2018.23.2.7.

Haigh, R. and Amaratunga, D. (2010) 'An integrative review of the built environment discipline's role in the development of society's resilience to disasters', International Journal of Disaster Resilience in the Built Environment, 1(1), pp. 11-24. doi: $10.1108 / 17595901011026454$.

Halvorson, S. J. and Hamilton, J. P. (2009) 'In the aftermath of the Qa'yamat: The Kashmir earthquake disaster in northern Pakistan', Disasters, 34(1), pp. 184-204. doi: 10.1111/j.1467-7717.2009.01124.x.

Jones, T. L. (2006) Mind the Gap! Post-disaster reconstruction and the transition from humanitarian relief. London. Available at: https://www.preventionweb.net/files/9080_MindtheGapFullreport1.pdf.

Kennedy, J. et al. (2008) 'The meaning of "build back better”: Evidence from post-tsunami Aceh and Sri Lanka', Journal of Contingencies and Crisis Management, 16(1), pp. 24-36. doi: 10.1111/j.1468-5973.2008.00529.x.

Khan, H., Vasilescu, L. G. and Khan, A. (2008) Disaster management cycle - A theoretical approach. University of Science and Technology. Available at: https://www.mnmk.ro/documents/2008/2008-6.pdf.

Khasalamwa, S. (2009) 'Is " build back better" a response to vulnerability? Analysis of the post-tsunami humanitarian interventions in Sri Lanka Understanding vulnerability', 63, pp. 73-89. doi: 10.1080/00291950802712152.

Mannakkara, S. (2015) “ Build Back Better ” principles for reconstruction', in Beer, M. et al. (eds) Encyclopedia of

Earthquake Engineering. doi: 10.1007/978-3-642-35344-4.

Mannakkara, S., Wilkinson, S. and Francis, T. R. (2014) “Build Back Better" principles for reconstruction, Encyclopedia of Earthquake Engineering. Berlin: Heidelberg: Springer Berlin Heidelberg. doi: 10.1007/978-3-642-36197-5_343-1.

Ministry of Disaster Managemennt (2009) Disaster Management Centre. Available at:

http://www.disastermin.gov.lk/web/index.php?option=com_content\&view=article\&id=54\&Itemid=78\&lang=en (Accessed: 6 February 2020).

Ministry of National Policies and Economic Affairs (2016) Sri Lanka post-disaster needs assessment. Colombo.

Priestley, M. and Hemingway, L. (2007) 'Disability and disaster recovery: A tale of two cities?', Journal of Social Work in

Disability \& Rehabilitation, 5(3-4), pp. 23-42. doi: 10.1300/J198vo5no3_02.

Robles, C. P. Q. (2019) Gender equality and women's empowerment in disaster recovery. Available at:

https://www.gfdrr.org/recovery-hub.

Salamati Nia, S. and Kulatunga, U. (2017) 'The importance of disaster management and impact of natural disasters on hospitals', in The 6th World Construction Symposium. Available at:

https://www.researchgate.net/publication/318128263_THE_IMPORTANCE_OF_DISASTER_MANAGEMENT_IMPACT_ OF_NATURAL_DISASTERS_ON_HOSPITALS.

Saunders, M., Lewis, P. and Thornhill, A. (2016) Research methods for business students. 7th edn. Harlow: Pearson Education Limited.

Seager, J. (2014) 'Disasters are gendered: What's new?', in In Reducing Disaster: Early Warning Systems For Climate Change. Netherlands: Springer, pp. 265-281. doi: 10.1007/978-94-017-8598-3_14.

Sharma, A. (2014) Disaster risk management: Inclusive. Kathmandu. Available at:

https://reliefweb.int/sites/reliefweb.int/files/resources/actionaid_inclusion_paper_final_170614_low.pdf.

Steele, P. et al. (2007) Disaster management policy and practice: Lessons for government, civil society, and the private sector in Sri Lanka. Colombo: Institute of Policy Studies of Sri Lanka. Available at:

https://www.researchgate.net/publication/309195537_Disaster_Management_Policy_and_Practice_in_Sri_Lanka_Sharin g_Lessons_among_Government_Civil_Society_and_Private_Sector.

Thurairajah, N., Amaratunga, D. and Haigh, R. (2008) 'Post disaster reconstruction as an opportunity for development : Women 's perspective', in CIB W89 International Conference on Building Education and research (BEAR). Sri Lanka, pp. 1106-1115. Available at: http://eprints.hud.ac.uk/id/eprint/22603/.

Tierney, K. (2015) 'Resilience and the Neoliberal Project', American Behavioral Scientist, 59(10), pp. 1327-1342. doi: $10.1177 / 0002764215591187$. 
UN Spider (2019) Risks and disasters. Available at: http://www.un-spider.org/risks-and-disasters (Accessed: 22 January 2020).

United Nations Development Programme (2009) Sri Lanka national report on disaster risk, poverty and human development relationship. Bangkok. Available at: https://www.preventionweb.net/english/hyogo/gar/backgroundpapers/documents/Chap3/Asia-overview/Sri-Lanka-DRAFT-march-o9.pdf.

United Nations Office for Disaster Risk Reduction (2019) Disaster risk reduction in Sri Lanka overview : Disasters in Sri

Lanka. Bangkok, Thailand. Available at: https://www.unisdr.org/files/68230_10srilankadrmstatusreport.pdf.

United Nations Economic and Social Commission for Asia and the Pacific (2012) Incheon Strategy to make the Right real for persons with disabilities in Asia and the Pacific. Available at:

http://www.unescapsdd.org/files/documents/PUB_Incheon-Strategy-EN.pdf.

United Nations Economic and Social Commission for Asia and the Pacific (2015) Disability-inclusive disaster risk reduction.

Bangkok. Available at: https://www.unescap.org/sites/default/files/pre-ods/E_CDR\%284\%29_INF4.pdf.

United Nations General Assembly (2017) Report of the open-ended intergovernmental expert working group on indicators and terminology relating to disaster risk reduction. Available at: https://www.unisdr.org/archive/51767.

United Nations International Strategy for Disaster Reduction (2005) The Hyogo framework for action 2005-2015: Building the resilience of nations and communities to disasters.

United Nations Children's Fund (2005) Building Back Better: A 12-month update on UNICEF's work to rebuild children's lives and restore hope since the Tsunami. UNICEF. Available at: https://www.unicef.org/TSUNAMI_E_BOOK_spreads.pdf. United Nations (2019) Disability and development report. New York. Available at: https://www.un.org/development/desa/disabilities/wp-content/uploads/sites/15/2019/o7/disability-report-chapter2.pdf. United Nations Development Programme (2018) Build Back Better. Available at:

https://www.lk.undp.org/content/srilanka/en/home/stories/Building-Back-Better.html (Accessed: 14 January 2020 ).

Wickramaratne, S. et al. (2012) 'Ranking of natural disasters in Sri Lanka for mitigation planning', International Journal of Disaster Resilience in the Built Environment, 3(2), pp. 115-132. doi: 10.1108/17595901211245198.

Wickramasinghe, K. (2014) 'Role of social protection in disaster management in Sri Lanka', Sri Lanka Journal of Social Sciences, 35(2), pp. 1-8. doi: 10.4038/sljss.v35i1-2.7297.

Zayas, J. et al. (2017) Build Back Better : Making inclusion work in disaster recovery in the aftermath of Typhoon Haiyan. Philippines. Available at:

https://www.researchgate.net/publication/320700392_Build_Back_Better_Making_Inclusion_Work_in_Disaster_Recove ry_in_the_Aftermath_of_Typhoon_Haiyan. 